\title{
Chromosomal assignment and deletion mapping of barley EST markers
}

\author{
Shuhei Nasuda ${ }^{1}$, Yukari Kikkawa ${ }^{1}$, Taizo Ashida ${ }^{1}$, A. K. M. Rafiqul Islam ${ }^{2}$, \\ Kazuhiro Sato ${ }^{3}$ and Takashi R. Endo ${ }^{1 *}$ \\ ${ }^{1}$ Laboratory of Plant Genetics, Graduate School of Agriculture, Kyoto University, \\ Kyoto 606-8502, Japan \\ ${ }^{2}$ Department of Plant Science, the University of Adelaide, SA 5064, Australia \\ ${ }^{3}$ Research Institute for Bioresources, Okayama University, \\ Kurashiki 710-0046, Japan
}

(Received 1 August 2005, accepted 24 October 2005)

\begin{abstract}
From about 10000 PCR-based EST markers of barley we chose 1421 EST markers that were demonstrated to be amplified differently by PCR between wheat (Triticum aestivum cv. Chinese Spring) and barley (Hordeum vulgare cv. Betzes). We assigned them to the seven barley chromosomes $(1 \mathrm{H}$ to $7 \mathrm{H})$ by PCR analysis using a set of wheat-barley chromosome addition lines. We successfully assigned 701 (49.3\%) EST markers to the barley chromosomes: 75 to $1 \mathrm{H}, 127$ to $2 \mathrm{H}, 119$ to $3 \mathrm{H}, 94$ to $4 \mathrm{H}, 108$ to $5 \mathrm{H}, 81$ to $6 \mathrm{H}$ and 97 to $7 \mathrm{H}$. By using a set of Betzes barley telosomic addition lines of Chinese Spring, we could successfully determine the chromosome-arm (S or L) location of at least $90 \%$ of the EST markers assigned to each barley chromosome. We conducted a trial mapping using 90 EST markers assigned to $7 \mathrm{HS}$ (49) or $7 \mathrm{HL}$ (41) and 19 wheat lines carrying $7 \mathrm{H}$ structural changes. More EST markers were found in the distal region than in the proximal region.
\end{abstract}

Key words: barley, chromosome mapping, EST, wheat-barley addition

\section{INTRODUCTION}

Barley (Hordeum vulgare, $2 \mathrm{n}=2 \mathrm{x}=14$, genome formula $\mathrm{HH}$ ) is one of the major crops cultivated in the temperate zones. Besides its agronomic importance, barley has been an important material for genetic and genomic studies of Triticeae, a tribe of the grass family. The advantages of barley as an experimental material over the other Triticeae species resides basically in its diploid nature; its DNA content (5000 Mbp per haploid genome) is one third of that of wheat (17000 Mbp per haploid genome) (Bennett and Leitch, 1995). This smaller genome size makes various molecular approaches of study more feasible in barley than in polyploid wheat. Comparative genomics revealed that the linear order of genes in Triticeae species is well conserved (for reviews, see Bennetzen 2000; Devos and Gale, 2000; Laurie and Devos, 2002) and that partial co-linearity can be traced in syntenic chromosomal segments of the rice genome; the only monocot genome whose draft sequence is available (the International Rice Genome Sequence Project (IRGSP)) (for reviews, see Feuillet and Keller, 2002; Ben-

Edited by Minoru Murata

* Corresponding author. E-mail: trendo@kais.kyoto-u.ac.jp netzen and Ma 2003).

Genetic chromosome maps have been constructed in barley with various molecular markers: restriction fragment length polymorphisms (RFLPs) (Kleinhofs et al., 1993), amplified fragment length polymorphisms (AFLPs) (Qi and Lindhout, 1997; Castiglioni et al., 1998), random amplified microsatellite polymorphisms (RAMPs) (Becker and Heun, 1995), simple sequence repeat (SSR)-based markers (Ramsay et al., 2000), and retrotransposon markers (Manninen et al., 2000). One of the most rapidly developing fields in barley genomics is EST (expressed sequence tag) markers, or sequenced cDNA fragments, which would enable us to access genes of interest in the genome. The Research Institute for Bioresources at Okayama University, Japan, and National Institute of Genetics, Japan, have sequenced and analyzed more than 140,000 clones of barley ESTs (Sato et al., unpublished), and converted about 10,000 EST sequences into PCRbased genetic markers. More than 1,000 of those EST markers have been incorporated into high-density barley genetic maps (Sato et al., 2004). Studies using EST information would surely open doors to new findings in the genomics of barley and related species. EST markers are also useful in constructing and characterizing BAC (bacterial artificial chromosome) libraries (Yu et al., 
2000; Saisho et al., 2003) and microarray systems (Close et al., 2004).

Genome maps provide primary information for cloning genes of interest. High-density genetic chromosome maps are available for barley (Hori et al., 2003). However, genetic maps, which are based on recombination values, do not necessarily represent actual physical locations of genes and molecular markers (DeScenzo and Wise, 1996). Such distortions of gene loci can be remedied by physical, or cytological, mapping. In barley, two cytogenetical methods have been used for the physical mapping of RFLP markers: One uses microisolated translocation chromosomes as the templates for PCR with primers designed from sequenced RFLP probes (Sorokin et al., 1994; Künzel et al., 2000); the other is deletion mapping using structural changes of a barley chromosome added to wheat (Serizawa et al., 2001a). The latter type of mapping employs common wheat stocks carrying structural aberrations of barley chromosomes that have been induced in wheat-barley addition lines using the gametocidal system (Shi and Endo, 1997, 1999, 2000). The same genetic system was used for the production of deletion stocks in common wheat (Endo 1988, 1990; Endo and Gill, 1996) that have been used extensively in the mapping of wheat RFLPs (Werner et al., 1992), AFLPs (Zhang et al., 2000) and ESTs (Gustafson et al., 2004; and associated papers).

Toward the goal of future large-scale physical mapping of barley EST markers, in this study we assigned barley EST markers to individual barley chromosomes and chromosome arms. Also, we attempted physical mapping of the EST markers assigned to $7 \mathrm{H}$ using 19 common wheat stocks carrying structural changes of chromosome $7 \mathrm{H}$ that had been generated using the gametocidal system.

\section{MATERIALS AND METHODS}

Plant materials We used a set of wheat-barley addition lines and their parental cultivars of wheat (Triticum aestivum cv. Chinese Spring, $2 \mathrm{n}=6 \mathrm{x}=42$, genome formula AABBDD) and barley (Hordeum vulgare cv. Betzes, $2 \mathrm{n}=2 \mathrm{x}=14, \mathrm{HH})$. The wheat-barley addition lines have pairs of barley chromosomes $(2 \mathrm{H}, 3 \mathrm{H}, 4 \mathrm{H}, 5 \mathrm{H}, 7 \mathrm{H})$ (Islam et al., 1981) and the respective chromosome arms (1HS, $2 \mathrm{HS}, 2 \mathrm{HL}, 3 \mathrm{HS}, 3 \mathrm{HL}, 4 \mathrm{HS}, 4 \mathrm{HL}, 5 \mathrm{HS}, 5 \mathrm{HL}, 6 \mathrm{HS}, 6 \mathrm{HL}$, 7HS, 7HL: 'S' and 'L' stand for the long arm and short arm of the chromosome, respectively) in the wheat genomic background (Islam, 1983). The methodology used to assign barley EST markers to individual chromosomes was described in Murai et al. (2000) and Serizawa et al. (2001b). Since the addition of $1 \mathrm{H}$ causes extreme meiotic abnormalities leading to complete sterility in Chinese Spring, we used a wheat line carrying $1 \mathrm{H}$ and $6 \mathrm{H}$ $\left(21^{\prime \prime}+1^{\prime} 1 \mathrm{H}+1^{\prime \prime} 6 \mathrm{H}\right)$, which is partially fertile (Islam and Shepherd, 2000) for the $1 \mathrm{H}$ addition line. These wheat genetic stocks were obtained from National Bioresources Project-Wheat (http://www.grs.nig.ac.jp/wheat/komugi/top/ top.jsp).

We used 19 stocks of Chinese Spring carrying structural changes of $7 \mathrm{H}$ with breakpoints in various regions (Fig. 1). They were originally isolated from a $7 \mathrm{H}$ addition line of Chinese Spring carrying a gametocidal chromosome (Shi and Endo, 2000) and were screened in this study for plants homozygous or hemizygous for the respective aberrant $7 \mathrm{H}$ chromosomes: Eight of them had breakpoints in the short arm, eight in the long arm, and three in the centromeric region. Four of the deletions (Fig. 1-e, -h, -j, and -k) were telosomes derived from primary deletion chromosomes. Two telocentric chromosomes (Fig. 1-1 and -s) are stable 7HS telosomes without the centromeric repetitive sequences that are present in all regular barley chromosomes (Nasuda et al., 2005).

EST primers We used three barley strains to construct cDNA libraries: 'H602', a wild barley strain classified as Hordeum vulgare ssp. spontaneum; 'Akashinriki', a cultivated, Japanese six-row hull-less food barley landrace; 'Haruna Nijo', a Japanese two-row malting barley. Five cDNA libraries were constructed as described in HarvEST (http://harvest.ucr.edu/). Cycle-sequencing was performed using ABI3700 DNA sequencers with BigDyeterminator (Applied Biosystems) from both the 3' and 5' ends of cDNA clones. Each read was base-called using a "phred" software package and was trimmed to remove the vector and poly-A and poly-T stretches. By using the "phred" base-calling quality score, high quality sequences $(\mathrm{QV}>=20)$ were selected from each read.

The 3' ESTs were assembled using a "phrap" software package, and a set of non-redundant sequences was developed. An EST with the longest sequence of high quality was selected from each contig to develop primer sets using the software package "Primer3". Sequences from singlets were also used to develop primer sets. For primer development the following conditions were used: $\mathrm{Tm}=60^{\circ} \mathrm{C}\left( \pm 2^{\circ} \mathrm{C}\right.$ between forward and reverse primers $)$, GC content $=50 \%( \pm 20 \%)$, and target size $=400 \mathrm{bp}(150$ bp to $500 \mathrm{bp}$ ). Thus, about 10,000 primer pairs were generated and about 5100 of them amplified a clear single PCR product in barley 'Betzes' but not in common wheat 'Chinese Spring' (Sato, unpublished). From the latter primer set we chose 1421 primer pairs for the detection of barley chromosomal segments in wheat.

DNA extraction Genomic DNA of plant materials was isolated with Plant DNAzol Reagent (Invitrogen). Plant leaves pulverized in liquid nitrogen were mixed with Plant DNAzol (Plant DNAzol: plant tissue $=0.3 \mathrm{ml}: 0.1$ g) and incubated at $25^{\circ} \mathrm{C}$ with shaking for $5 \mathrm{~min}$. Chloroform $(0.3 \mathrm{ml}$ for $0.1 \mathrm{~g}$ of plant tissue) was added to the mixture, and it was further incubated at $25^{\circ} \mathrm{C}$ with shak- 


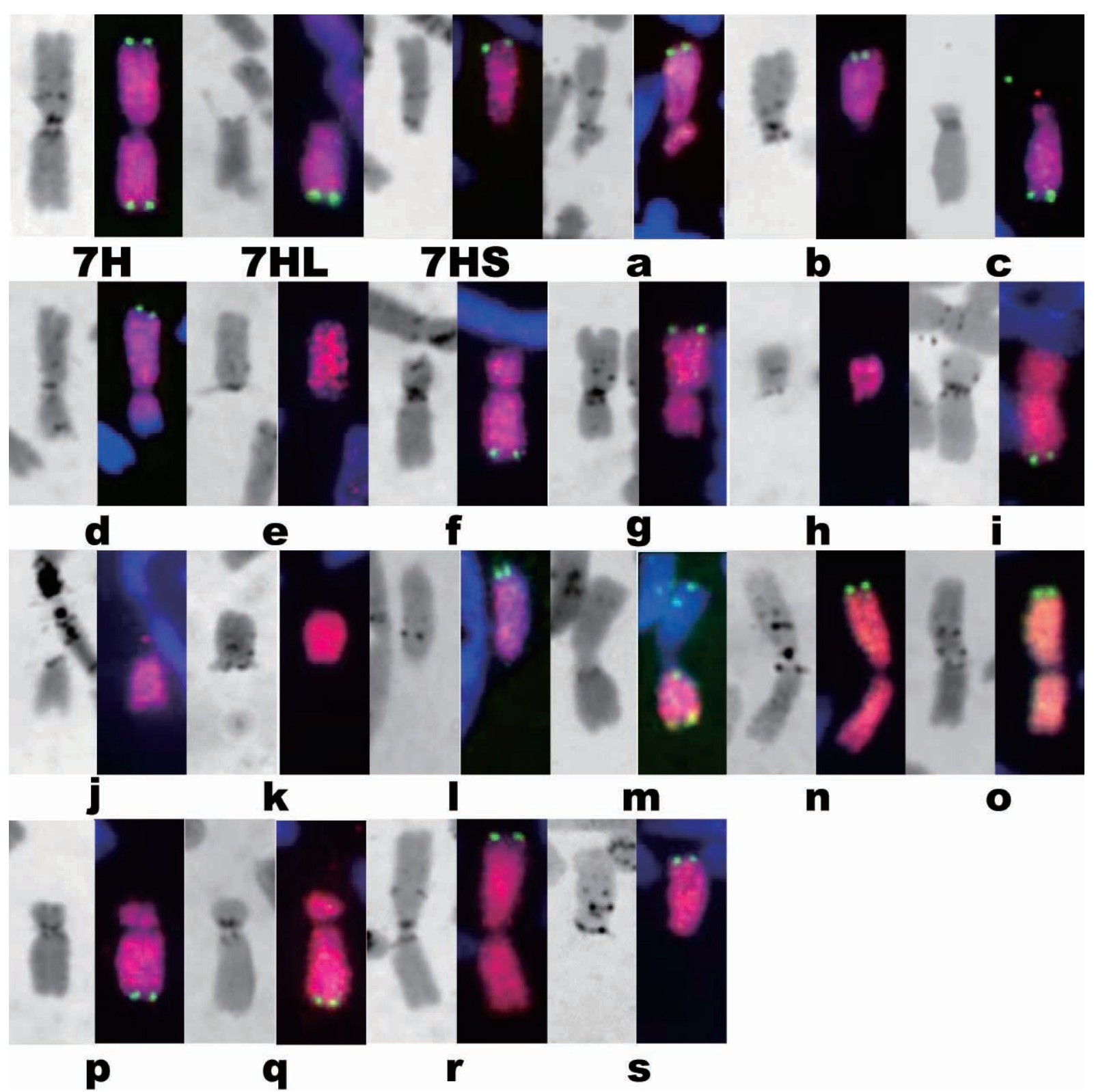

Fig. 1. C-banding (left) and GISH/FISH (right) images of normal 7H, 7HS and 7HL, and structural aberrations of chromosome 7H (a to $\mathrm{s}$ ). The probes used were barley total genomic DNA (red) and a barley subtelomeric repeat sequence HvT01 (green). Chromosomes were counterstained with DAPI (blue). Bar $=10 \mu \mathrm{m}$.

ing for another $5 \mathrm{~min}$. Following extraction, the mixture was centrifuged at $12000 \times \mathrm{g}$ for $10 \mathrm{~min}$, and the resulting supernatant, (the aqueous phases) was transferred to a fresh tube. For the precipitation of DNAs, the aqueous phase was mixed with $0.225 \mathrm{ml}$ of $100 \%$ ethanol per 0.1 $\mathrm{g}$ of plant tissue. The precipitated DNAs were centrifuged at $5000 \times \mathrm{g}$ for $4 \mathrm{~min}$, and the resulting supernatants were removed. DNA pellets were washed with Plant DNAzol-ethanol wash solution (Plant DNAzol: ethanol $=1: 0.75$ ) and 75\% ethanol, and then centrifuged at $5000 \times \mathrm{g}$ for $4 \mathrm{~min}$. After the removal of ethanol, the DNA pellets were dried in vacuum chamber and dissolved in $100 \mu \mathrm{l}$ of TE buffer per $0.1 \mathrm{~g}$ of plant tissue.
Polymerase Chain Reaction (PCR) Once isolated, 1 $\mu \mathrm{l}$ of DNA (10 $\mathrm{ng} / \mu \mathrm{l})$ was used as a template in PCR (iCycler, BioRad) with the 1421 barley EST markers. The PCR reagent mixture consisted of $1 \mu \mathrm{l}$ of $10 \times$ PCR buffer, $0.8 \mu \mathrm{l}$ of dNTP mixture $(2.5 \mathrm{mM}$ each, Amersham Biosciences), $0.25 \mu \mathrm{l}$ of primers ( $10 \mathrm{pmol} / \mu \mathrm{l}), 0.05 \mu \mathrm{l}$ of Taq polymerase (Roche), and $6.65 \mu \mathrm{l}$ of $\mathrm{dH}_{2} \mathrm{O}$. The PCR conditions were as follows: $94^{\circ} \mathrm{C} \times 2 \mathrm{~min}, 5$ cycles of $94^{\circ} \mathrm{C} \times$ $30 \mathrm{sec}, 65^{\circ} \mathrm{C} \times 30 \mathrm{sec}$ (with the temperature subsequently decreased $1^{\circ} \mathrm{C}$ per cycle), and $72^{\circ} \mathrm{C} \times 1 \mathrm{~min}, 35$ cycles of $94^{\circ} \mathrm{C} \times 30 \mathrm{sec}, 60^{\circ} \mathrm{C} \times 30 \mathrm{sec}$, and $70^{\circ} \mathrm{C} \times 1 \mathrm{~min}$, and $70^{\circ} \mathrm{C}$ $\times 7 \mathrm{~min}$. PCR products were checked by agarose (Agarose $\mathrm{S}$, Nippon gene) gel eletrophoresis at $200 \mathrm{~V}$ for $20 \mathrm{~min}$. 


\section{RESULTS AND DISCUSSION}

Assignment of the barley EST markers to individual chromosomes and chromosome arms Using the 1421 primer pairs that showed differential PCR amplification between wheat and barley, we conducted PCR in the wheat-barley chromosome addition lines to sort the EST markers into seven chromosomal groups. Except for $6 \mathrm{H}$, when the PCR product of an EST was seen in only one of the barley addition lines (Fig. 2A), we assigned the EST to the critical barley chromosome. We regarded EST markers that were amplified in both $1 \mathrm{H}$ addition and $6 \mathrm{H}$ addition lines as being specific for $6 \mathrm{H}$ because the $1 \mathrm{H}$ addition line carries a pair of $6 \mathrm{H}$ (see Materials and Methods) (Fig. 2B), although some of these markers might also have been located on $1 \mathrm{H}$. We thereby successfully assigned 701 EST markers $(49.3 \%)$ to single barley chromosomes: 75 to $1 \mathrm{H}, 127$ to $2 \mathrm{H}, 119$ to $3 \mathrm{H}, 94$ to $4 \mathrm{H}, 108$ to $5 \mathrm{H}, 81$ to $6 \mathrm{H}$, and 97 to $7 \mathrm{H}$ (Table 1). The most marker-rich chromosome was chromosome $2 \mathrm{H}$ (127 markers) and the least marker-rich was $1 \mathrm{H}$ (75 markers), with an average of 100.1 markers per chromosome. The chi-square test $\left(\chi^{2}=21.6, \mathrm{df}=6\right)$ rejected the random chromosomal distribution of the EST markers at the $1 \%$ level. Some EST markers were amplified in multiple barley addition lines: 16 EST markers were amplified in two lines (except for the combination of the $1 \mathrm{H}$ and $6 \mathrm{H}$ additions), 17 markers in three lines, 10 markers in four lines, 7 markers in 5 lines, 6 markers in six lines, and 20 markers in seven lines. This suggests that some of the barley EST markers are multi-copy and dispersed on different chromosomes. We could not assign the rest of the EST markers to barley chromosomes due to inexplicable PCR amplification results, such as no amplification in barley or amplification in wheat. These unexpected PCR amplification findings for the remaining unassigned EST markers may be due partly to the difference between the cultivar from which the template DNA was extracted (Betzes) and those from which the EST markers were generated (Haruna Nijo, Akashinriki and H602).

Using the 13 wheat-barley addition lines that were telocentric except for $1 \mathrm{HS}$, we attempted to allocate the 701 EST markers assigned to the individual barley chromosomes to their short and long arms. More than 90\% of the EST markers were successfully allocated to either the short arm or the long arm; namely, they were amplified by PCR in only one telocentric line of the critical chromosome (Table 1, Fig. 2C). We could not allocate the remaining EST markers due to either technical problems or unexplainable results of PCR amplification. The primer sequences of all EST markers that were allocated to specific chromosome arms are available as supplemental data (http://www.rib.okayama-u.ac.jp/barley/barley_deletion_mapping_est.htm).

Deletion mapping of chromosome $7 \mathbf{H}$ For physical mapping of chromosome $7 \mathrm{H}$, we used the 90 EST markers assigned to either 7HS (49) or 7HL (41). Template

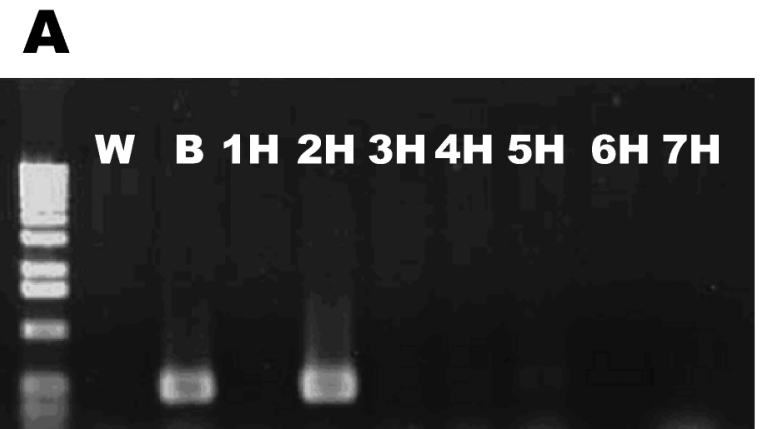

B
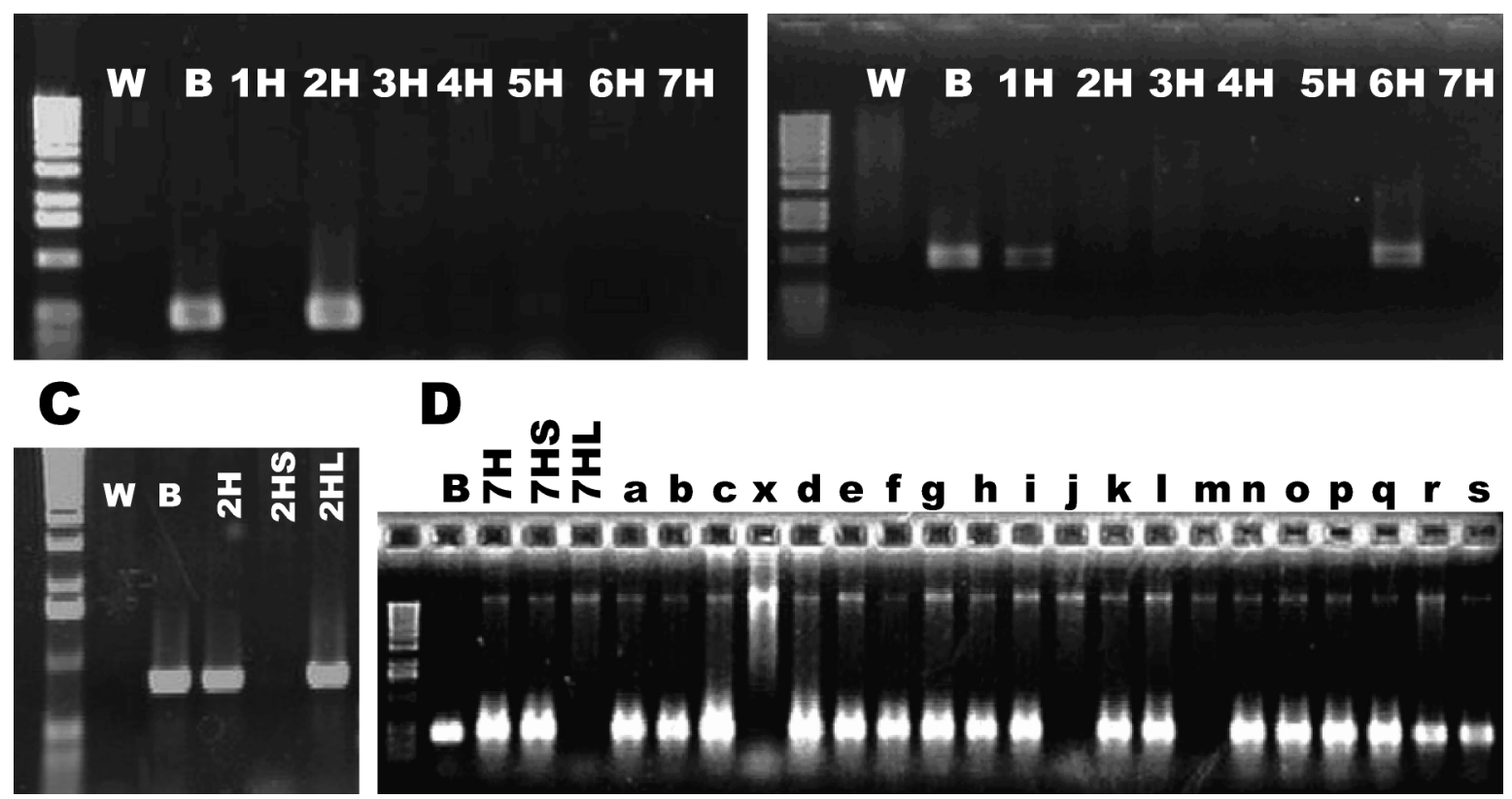

D

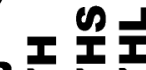

BI I I a b c x d e f g h j k m m o p q r s

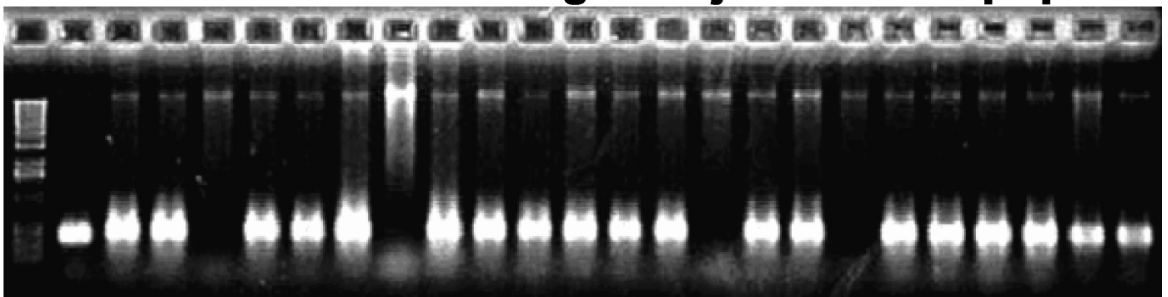

Fig. 2. PCR analysis to assign barley EST markers to the various barley chromosomes (A: k00932, B: k01114), chromosome arms (C: k03376) and sub-arm regions (D: k03148). "W" and "B" stands for wheat and barley, respectively, and "x" in (D) is a control derivative plant without $7 \mathrm{H}$ chromatin. The leftmost lane of each PCR gel image is a 1-kb DNA marker ladder. 
Table 1. Assignment of barley ESTs to chromosomes and chromosome arms

\begin{tabular}{|c|c|c|c|c|c|c|c|}
\hline \multirow{2}{*}{$\begin{array}{l}\text { Barley } \\
\text { chromosome }\end{array}$} & \multirow{2}{*}{$\begin{array}{l}\text { No. ESTs } \\
\text { assigned }\end{array}$} & \multicolumn{6}{|c|}{ ESTs derived from ${ }^{1)}$} \\
\hline & & HN-GS & HN-LSL & HN-LH & HN-Mis & AK-L & H602-LH \\
\hline $1 \mathrm{H}$ & 75 & 18 & 10 & 12 & 0 & 18 & 17 \\
\hline 1HS & 17 & 4 & 4 & 4 & 0 & 2 & 3 \\
\hline $1 \mathrm{HL}$ & 51 & 12 & 6 & 8 & 0 & 14 & 11 \\
\hline$?^{2)}$ & 7 & & & & & & \\
\hline $2 \mathrm{H}$ & 127 & 34 & 16 & 24 & 2 & 30 & 21 \\
\hline $2 \mathrm{HS}$ & 49 & 11 & 8 & 6 & 1 & 12 & 11 \\
\hline $2 \mathrm{HL}$ & 68 & 20 & 8 & 17 & 1 & 13 & 9 \\
\hline$?$ & 10 & & & & & & \\
\hline $3 \mathrm{H}$ & 119 & 36 & 9 & 25 & 0 & 30 & 19 \\
\hline $3 \mathrm{HS}$ & 37 & 7 & 3 & 10 & 0 & 10 & 7 \\
\hline $3 \mathrm{HL}$ & 70 & 23 & 6 & 14 & 0 & 16 & 11 \\
\hline$?$ & 12 & & & & & & \\
\hline $4 \mathrm{H}$ & 94 & 28 & 9 & 19 & 0 & 12 & 26 \\
\hline $4 \mathrm{HS}$ & 33 & 9 & 1 & 6 & 0 & 5 & 12 \\
\hline $4 \mathrm{HL}$ & 55 & 16 & 8 & 13 & 0 & 5 & 13 \\
\hline$?$ & 6 & & & & & & \\
\hline $5 \mathrm{H}$ & 108 & 36 & 15 & 22 & 0 & 20 & 15 \\
\hline $5 \mathrm{HS}$ & 23 & 8 & 3 & 5 & 0 & 2 & 5 \\
\hline $5 \mathrm{HL}$ & 77 & 24 & 11 & 16 & 0 & 17 & 9 \\
\hline$?$ & 8 & & & & & & \\
\hline $6 \mathrm{H}$ & 81 & 14 & 12 & 20 & 0 & 19 & 17 \\
\hline $6 \mathrm{HS}$ & 36 & 10 & 5 & 7 & 0 & 10 & 4 \\
\hline $6 \mathrm{HL}$ & 41 & 4 & 7 & 13 & 0 & 7 & 10 \\
\hline$?$ & 4 & & & & & & \\
\hline $7 \mathrm{H}$ & 97 & 27 & 15 & 17 & 1 & 20 & 17 \\
\hline 7HS & 49 & 17 & 11 & 8 & 1 & 8 & 4 \\
\hline 7HL & 41 & 9 & 4 & 9 & 0 & 9 & 10 \\
\hline$?$ & 7 & & & & & & \\
\hline Total & 701 & 193 & 86 & 139 & 3 & 149 & 132 \\
\hline $\begin{array}{l}\text { 1) Sources of } \\
\text { GS), Haru } \\
\text { at heading } \\
\text { vegetative }\end{array}$ & $\begin{array}{l}\text { T clones a } \\
\text { Nijo, leav } \\
\text { age (HN-I } \\
\text { ge (AK-L }\end{array}$ & $\begin{array}{l}\text { bbrevia } \\
\text { t second } \\
\text { Haruna } \\
\text { d H602, }\end{array}$ & $\begin{array}{l}\text { as follow } \\
\text { af stage } \\
\text { jo, miscel } \\
\text { p three } 1\end{array}$ & $\begin{array}{l}\text { s: Harun } \\
\text { HN-LSL) } \\
\text { laneous (l } \\
\text { aves at h }\end{array}$ & $\begin{array}{l}\text { Nijo, germ } \\
\text { Haruna } \mathrm{N} \\
\text { N-Mis), A } \\
\text { ading sta }\end{array}$ & $\begin{array}{l}\text { ating s } \\
\text {, top tl } \\
\text { shinrik } \\
\text { (H602- }\end{array}$ & $\begin{array}{l}\text { ots (HN- } \\
\text { ee leaves } \\
\text { leaves at } \\
\text { I). }\end{array}$ \\
\hline
\end{tabular}

DNAs for PCR were extracted from wheat plants carrying various structural aberrations of $7 \mathrm{H}$, including telocentric 7HS and 7HL (a to s; for their breakpoints, see Fig. 1 and Fig. 3). We examined the presence or absence of the EST markers in those lines by PCR analysis (Fig. 2D). We identified the position of an EST as being between the closest breakpoints of two structurally modified $7 \mathrm{H}$ chromosomes when one of them retained the EST and the other did not. Using the collected data, we were able to put the 90 EST markers in order (Table 2). There were some contradictions between the PCR amplifications and cytological features of $7 \mathrm{H}$ aberrations. For example,
EST marker k03433 was amplified in the 7HS telosomic line but was not amplified in the lines carrying aberrant $7 \mathrm{H}$ chromosomes "g" and " $\mathrm{r}$ ", which apparently had the whole 7HS arm (Table 2, Fig. 1). These contradictions might be due to sub-microscopic interstitial deletions or translocations of $7 \mathrm{H}$ chromosome segments.

Using the arm ratio $(\mathrm{L} / \mathrm{S}=0.92)$ of the intact $7 \mathrm{H}$ chromosome and the arm ratios of deleted $7 \mathrm{H}$ chromosomes "i" and "g" (five chromosomes were measured) (see Serizawa et al. 2001a), we calculated that "i" retained about $47 \%$ of the length of 7HS and that "g" retained about $68 \%$ of the length of $7 \mathrm{HL}$. Eleven out of the $497 \mathrm{HS}$ EST markers 


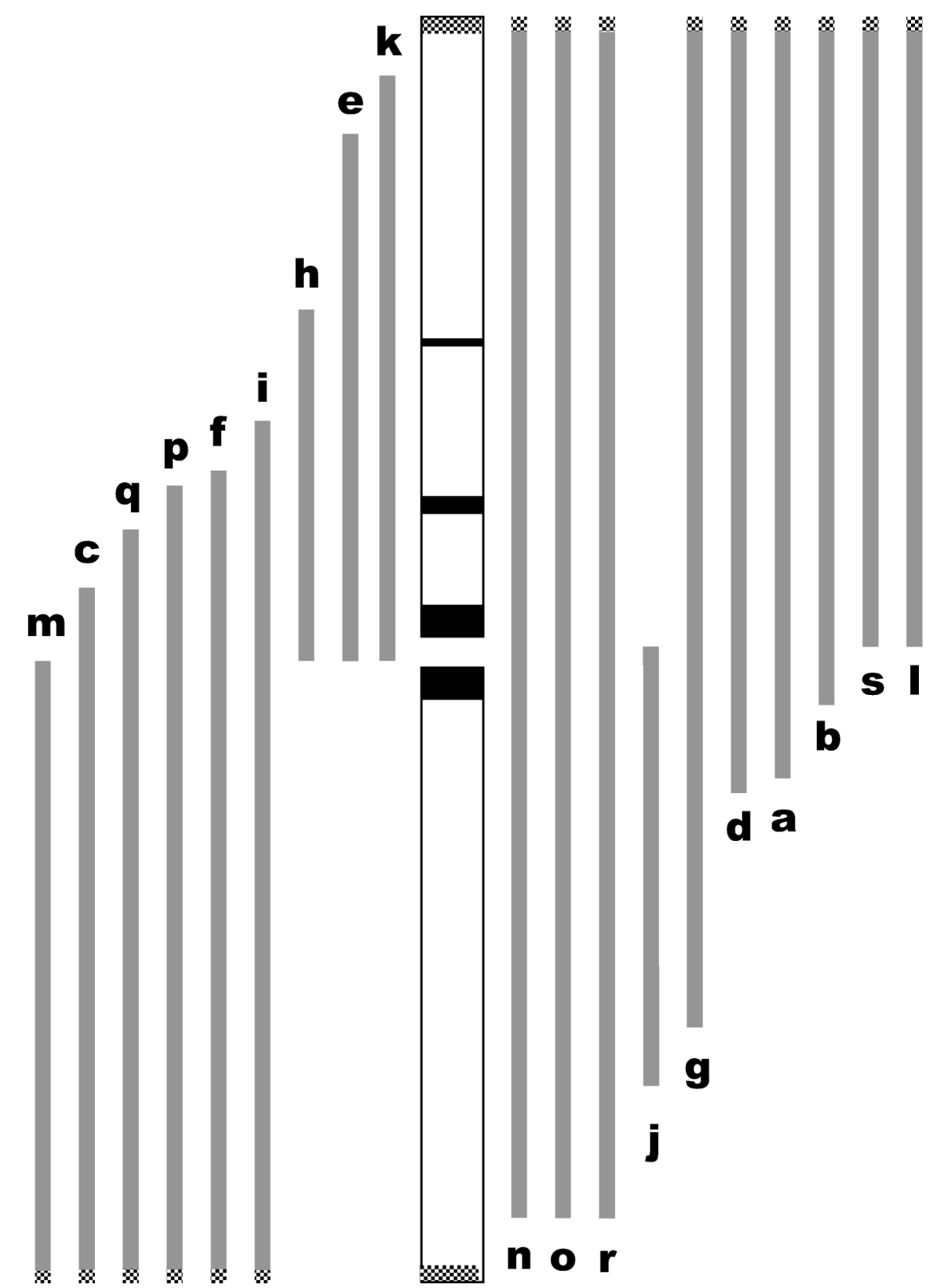

Fig. 3. Schematic representations of the remaining barley segments of the $7 \mathrm{H}$ structural aberrations.

were present in "i" and 17 out of the 41 HL EST markers were present in "g". On 7HS, $77.6 \%$ of the EST markers were located in the distal region accounting for ca. $53 \%$ of its length and on 7HL, 58.5\% of the EST markers were located in the distal region accounting for about $32 \%$ of its length (Table 2). Thus, relatively more EST markers were allocated in the distal region than in the proximal region. Although gene expression is generally regarded as being suppressed in the centromeric region due to the presence of heterochromatin and various types of repetitive sequences, two EST markers, k03717 and k00940, seem to be present in the centromeric region. Neither of these EST markers was amplified in the 7HS telosomic line, but both were amplified in the lines carrying aberrant $7 \mathrm{H}$ chromosomes that were apparently devoid of the 7HL arm: k03717 was amplified in the lines carrying aberrant 7H chromosomes, namely, "e", "k", and "l", and k00940 was amplified in "e", "h", "l”, and "s".

By mapping those EST markers, we could distinguish the breakpoints of aberrant $7 \mathrm{H}$ chromosomes that were indistinguishable by cytological observation. For example, the breakpoint of "f" was indicated to be distal to the breakpoints of "p" based on the PCR data (Table 2). From this small-scale attempt at cytological mapping, we conclude that structurally modified barley chromosomes induced using the gametocidal system would be useful 
Table 2. Presence or absence of the ESTs in the $7 \mathrm{H}$ lines

\begin{tabular}{|c|c|c|c|c|c|c|c|c|c|c|c|c|c|c|c|c|c|c|c|c|c|}
\hline \multirow{2}{*}{$\mathrm{EST}$} & \multirow{2}{*}{ Region2) } & & & & & & & & & & & & & & & & & & & & \\
\hline & & $7 \mathrm{HS}$ & $7 \mathrm{HL}$ & $\mathrm{k}$ & $\mathrm{e}$ & $\mathrm{h}$ & i & $\mathrm{f}$ & $\mathrm{p}$ & $q$ & $\mathrm{c}$ & $\mathrm{m}$ & 1 & $\mathrm{~s}$ & $\mathrm{~b}$ & $\mathrm{a}$ & $\mathrm{d}$ & $\mathrm{g} \quad \mathrm{j}$ & $\mathrm{r}$ & o & $\mathrm{n}$ \\
\hline & Telomere & & & & & & & & & & & & & & & & & & & & \\
\hline k01030 & $-\mathrm{k}$ & $*$ & & & & & & & & & & & $*$ & $*$ & $*$ & $*$ & $*$ & $*$ & $*$ & $*$ & * \\
\hline k01390 & $-\mathrm{k}$ & $*$ & & & & & & & & & & & $*$ & $*$ & $*$ & $*$ & $*$ & $*$ & $*$ & $*$ & * \\
\hline k03350 & $-\mathrm{k}$ & $*$ & & & & & & & & & & & $*$ & $*$ & $*$ & $*$ & $*$ & $*$ & $*$ & $*$ & * \\
\hline k03433 & $-\mathrm{k}$ & $*$ & & & & & & & & & & & $*$ & $*$ & $*$ & $*$ & $*$ & - & - & $*$ & * \\
\hline k00176 & $-\mathrm{k}$ & $*$ & & & & & & & & & & & $*$ & $*$ & $*$ & $*$ & $*$ & $*$ & $*$ & & * \\
\hline k04169 & $-\mathrm{k}$ & $*$ & & & & & & & & & & & $*$ & $*$ & $*$ & $*$ & $*$ & $*$ & $*$ & $*$ & * \\
\hline k02183 & $-\mathrm{k}$ & $*$ & & & & & & & & & & & $*$ & $*$ & $*$ & $*$ & $*$ & $*$ & $*$ & $*$ & * \\
\hline k04981 & $-\mathrm{k}$ & $*$ & & & & & & & & & $* ?$ & & $*$ & $*$ & $*$ & * & $*$ & $*$ & $*$ & $*$ & * \\
\hline k01454 & $\mathrm{k}-\mathrm{e}$ & $*$ & & $*$ & & & & & & & & & $*$ & $*$ & $*$ & $*$ & $*$ & $*$ & $*$ & $*$ & * \\
\hline k04783 & $\mathrm{k}-\mathrm{e}$ & $*$ & & $*$ & & & & & & & & & $*$ & $*$ & $*$ & $*$ & $*$ & $*$ & $*$ & $*$ & * \\
\hline k05012 & $\mathrm{k}-\mathrm{e}$ & $*$ & & $*$ & & & & & & & & & $*$ & $*$ & $*$ & $*$ & $*$ & $*$ & $*$ & $*$ & * \\
\hline k00076 & $\mathrm{k}-\mathrm{e}$ & $*$ & & $*$ & & & & & & & & & $*$ & $*$ & $*$ & $*$ & $*$ & $*$ & $*$ & $*$ & * \\
\hline k00111 & $\mathrm{k}-\mathrm{e}$ & $*$ & & $*$ & & & & & & $* ?$ & & & $*$ & $*$ & $*$ & $*$ & $*$ & $*$ & $*$ & $*$ & * \\
\hline k00987 & e-h & $*$ & & $*$ & * & & & & & & & & $*$ & $*$ & - & $*$ & $*$ & $*$ & $*$ & $*$ & * \\
\hline k01346 & $e-h$ & $*$ & & $*$ & * & & & & & & & & $*$ & $*$ & $*$ & $*$ & $*$ & $*$ & $*$ & $*$ & * \\
\hline k02995 & $e-h$ & $*$ & & $*$ & * & & & & & & & & $*$ & $*$ & $*$ & $*$ & $*$ & $*$ & $*$ & $*$ & * \\
\hline k03425 & e-h & $*$ & & $*$ & * & & & & & & & & $*$ & $*$ & $*$ & $*$ & $*$ & $*$ & $*$ & $*$ & * \\
\hline k04730 & $e-h$ & $*$ & & $*$ & * & & & & & & & & $*$ & $*$ & $*$ & $*$ & $*$ & $*$ & $*$ & $*$ & * \\
\hline k04925 & e-h & $*$ & & - & $*$ & & & & & & & & $*$ & $*$ & $*$ & $*$ & $*$ & $*$ & $*$ & $*$ & * \\
\hline k05008 & e-h & $*$ & & $*$ & * & & & & & & & & $*$ & $*$ & $*$ & $*$ & $*$ & $*$ & $*$ & $*$ & * \\
\hline k05031 & $e-h$ & $*$ & & $*$ & * & & & & & & & & $*$ & $*$ & $*$ & $*$ & $*$ & $*$ & $*$ & $*$ & * \\
\hline k05069 & e-h & $*$ & & * & $*$ & & & & & & & & $*$ & $*$ & $*$ & $*$ & $*$ & $*$ & $*$ & $*$ & $*$ \\
\hline k00174 & $e-h$ & $*$ & & $*$ & * & & & & & & & & $*$ & $*$ & $*$ & $*$ & $*$ & $*$ & $*$ & $*$ & * \\
\hline k00540 & e-h & $*$ & & $*$ & * & & & & & & & & $*$ & $*$ & $*$ & $*$ & $*$ & $*$ & $*$ & $*$ & * \\
\hline k00859 & e-h & $*$ & & * & $*$ & & & & & & & & $*$ & $*$ & $*$ & $*$ & $*$ & $*$ & $*$ & $*$ & * \\
\hline k02078 & e-h & $*$ & & $*$ & * & & & & & & & & $*$ & $*$ & $*$ & $*$ & $*$ & $*$ & $*$ & $*$ & * \\
\hline k02193 & e-h & $*$ & & $*$ & * & & & & & & & & $*$ & $*$ & $*$ & $*$ & $*$ & $*$ & $*$ & $*$ & * \\
\hline k03970 & e-h & $*$ & & $*$ & * & & & & & & & & $*$ & $*$ & $*$ & $*$ & $*$ & $*$ & $*$ & $*$ & * \\
\hline k01228 & $\mathrm{h}-\mathrm{i}$ & $*$ & & $*$ & $*$ & $*$ & & & & & & & $*$ & $*$ & $*$ & $*$ & $*$ & $*$ & $*$ & $*$ & $*$ \\
\hline k03174 & $h-i$ & $*$ & & $*$ & $*$ & $*$ & & & & & & & $*$ & $*$ & $*$ & $*$ & $*$ & $*$ & $*$ & $*$ & * \\
\hline k03210 & $h-i$ & $*$ & & $*$ & * & $*$ & & & & & & & $*$ & $*$ & $*$ & $*$ & $*$ & $*$ & $*$ & $*$ & * \\
\hline k03325 & $h-i$ & $*$ & & $*$ & * & $*$ & & & & & & & $*$ & $*$ & $*$ & $*$ & $*$ & $*$ & $*$ & $*$ & * \\
\hline k05047 & $h-i$ & $*$ & & $*$ & $*$ & $*$ & & & & & & & $*$ & $*$ & $*$ & $*$ & $*$ & $*$ & $*$ & $*$ & * \\
\hline k00300 & $\mathrm{h}-\mathrm{i}$ & $*$ & & $*$ & * & $*$ & & & & & & & $*$ & $*$ & $*$ & $*$ & $*$ & $*$ & $*$ & $*$ & * \\
\hline k04001 & $\mathrm{h}-\mathrm{i}$ & $*$ & & $*$ & $*$ & $*$ & & & & & & & $*$ & $*$ & $*$ & $*$ & $*$ & $*$ & $*$ & $*$ & * \\
\hline k04020 & h-i & $*$ & & $*$ & $*$ & $*$ & & & & & & & $*$ & $*$ & $*$ & $*$ & $*$ & $*$ & $*$ & $*$ & * \\
\hline k04975 & $h-i$ & $*$ & & $*$ & * & $*$ & & & & & $* ?$ & & $*$ & $*$ & $*$ & $*$ & $*$ & $*$ & $*$ & $*$ & * \\
\hline k02547 & $h-i$ & $*$ & & * & $*$ & $*$ & & & & & $* ?$ & & $*$ & $*$ & $*$ & $*$ & $*$ & $*$ & $*$ & $*$ & * \\
\hline k03353 & i-f & $*$ & & $*$ & $*$ & $*$ & * & & & & & & $*$ & $*$ & $*$ & $*$ & $*$ & $*$ & $*$ & $*$ & * \\
\hline k00901 & $f-p$ & $*$ & & $*$ & * & $*$ & $*$ & $*$ & & & & & $*$ & $*$ & $*$ & $*$ & $*$ & $*$ & $*$ & $*$ & * \\
\hline k00471 & $f-p$ & $*$ & & $*$ & * & $*$ & * & $*$ & & & & & $*$ & $*$ & $*$ & $*$ & $*$ & $*$ & $*$ & $*$ & $*$ \\
\hline k02344 & $f-p$ & $*$ & & * & $*$ & $*$ & * & $*$ & & & & & $*$ & $*$ & $*$ & $*$ & $*$ & $*$ & $*$ & $*$ & * \\
\hline k02414 & $f-p$ & $*$ & & $*$ & * & $*$ & * & $*$ & & & & & $*$ & $*$ & $*$ & $*$ & $*$ & $*$ & $*$ & $*$ & * \\
\hline k00896 & $\mathrm{p}-\mathrm{c}$ & $*$ & & $*$ & * & $*$ & * & $*$ & $*$ & $*$ & & & $*$ & $*$ & $*$ & $*$ & $*$ & $*$ & $*$ & $*$ & * \\
\hline k04944 & $\mathrm{p}-\mathrm{c}$ & $*$ & & $*$ & $*$ & $*$ & * & $*$ & $*$ & $*$ & & & $*$ & $*$ & $*$ & $*$ & & $*$ & $*$ & $*$ & * \\
\hline k02558 & $\mathrm{p}-\mathrm{c}$ & $*$ & & $*$ & * & $*$ & $*$ & $*$ & $*$ & $*$ & & & $*$ & $*$ & $*$ & $*$ & $*$ & $*$ & $*$ & $*$ & * \\
\hline k03148 & c- & $*$ & & * & $*$ & $*$ & * & * & $*$ & $*$ & $*$ & & $*$ & $*$ & $*$ & $*$ & $*$ & $*$ & $*$ & $*$ & * \\
\hline k02620 & $c-$ & $*$ & & $*$ & $*$ & $*$ & * & - & $*$ & $*$ & $*$ & & $*$ & $*$ & $*$ & $*$ & $*$ & $*$ & $*$ & $*$ & * \\
\hline k01578 & $c-$ & $*$ & & $*$ & * & $*$ & $*$ & $*$ & $*$ & $*$ & $*$ & & - & - & $*$ & $*$ & $*$ & $*$ & $*$ & $*$ & * \\
\hline
\end{tabular}




\begin{tabular}{|c|c|c|c|c|c|c|c|c|c|c|c|c|c|c|c|c|c|c|c|c|c|c|}
\hline & & $7 \mathrm{HS}$ & $7 \mathrm{HL}$ & $\mathrm{k}$ & $\mathrm{e}$ & $\mathrm{h}$ & $\mathrm{i}$ & $f$ & $\mathrm{p}$ & $q$ & $\mathrm{c}$ & $\mathrm{m}$ & 1 & $\mathrm{~s}$ & $\mathrm{~b}$ & $\mathrm{a}$ & $\mathrm{d}$ & $\mathrm{g}$ & $\mathrm{j}$ & $\mathrm{r}$ & o & $\mathrm{n}$ \\
\hline & Centromere & & & & & & & & & & & & & & & & & & & & & \\
\hline k03717 & -1 & & $*$ & $* ?$ & $* ?$ & - & $*$ & $*$ & $*$ & $*$ & $*$ & $*$ & $* ?$ & - & - & * & - & - & $*$ & $*$ & $*$ & $*$ \\
\hline k00940 & -1 & & $*$ & & $* ?$ & $* ?$ & $*$ & $*$ & $*$ & $*$ & - & - & $* ?$ & $* ?$ & $*$ & $*$ & $*$ & $*$ & $*$ & $*$ & $*$ & $*$ \\
\hline k01038 & $\mathrm{b}-\mathrm{a}$ & & $*$ & & & & $*$ & $*$ & $*$ & $*$ & $*$ & $*$ & & & & $*$ & $*$ & $*$ & $*$ & $*$ & $*$ & $*$ \\
\hline k01156 & $\mathrm{b}-\mathrm{a}$ & & $*$ & & & & $*$ & $*$ & $*$ & $*$ & $*$ & $*$ & & & & $*$ & $*$ & $*$ & $*$ & $*$ & $*$ & $*$ \\
\hline k03439 & $\mathrm{b}-\mathrm{a}$ & & $*$ & & & & $*$ & $*$ & $*$ & $*$ & $*$ & $*$ & & & & $*$ & $*$ & $*$ & $*$ & $*$ & $*$ & $*$ \\
\hline k00269 & $\mathrm{b}-\mathrm{a}$ & & $*$ & & & & $*$ & $*$ & $*$ & $*$ & $*$ & $*$ & & & & $*$ & $*$ & $*$ & $*$ & $*$ & $*$ & $*$ \\
\hline k00199 & $b-a$ & & $*$ & & & & $*$ & $*$ & $*$ & $*$ & $*$ & $*$ & & & & $*$ & $*$ & $*$ & $*$ & $*$ & $*$ & $*$ \\
\hline k02117 & $\mathrm{b}-\mathrm{a}$ & & $*$ & & & & - & - & $*$ & $*$ & $*$ & $*$ & & & & $*$ & $*$ & $*$ & $*$ & $*$ & $*$ & $*$ \\
\hline k04254 & $\mathrm{b}-\mathrm{a}$ & & $*$ & & & & $*$ & $*$ & $*$ & $*$ & $*$ & $*$ & & & & * & $*$ & $*$ & $*$ & $*$ & $*$ & $*$ \\
\hline k04058 & a-d & & $*$ & & & & $*$ & $*$ & $*$ & $*$ & $*$ & $*$ & & & & & $*$ & $*$ & $*$ & $*$ & $*$ & $*$ \\
\hline k00952 & $d-g$ & & $*$ & & & & $*$ & $*$ & $*$ & $*$ & $*$ & $*$ & & & & & & $*$ & $*$ & $*$ & $*$ & $*$ \\
\hline k01200 & $d-g$ & & $*$ & & & & $*$ & $*$ & $*$ & $*$ & $*$ & $*$ & & & & & & $*$ & $*$ & $*$ & $*$ & $*$ \\
\hline k03326 & $d-g$ & & $*$ & & & & $*$ & $*$ & $*$ & $*$ & $*$ & $*$ & & & & & & $*$ & $*$ & $*$ & $*$ & $*$ \\
\hline k03595 & $d-g$ & & $*$ & & & & $*$ & $*$ & $*$ & $*$ & $*$ & $*$ & & & & & & $*$ & $*$ & $*$ & $*$ & $*$ \\
\hline k05059 & $d-g$ & & $*$ & & & & $*$ & $*$ & $*$ & $*$ & $*$ & $*$ & & & & & & $*$ & $*$ & $*$ & $*$ & $*$ \\
\hline k00250 & $d-g$ & & $*$ & & & & $*$ & $*$ & $*$ & $*$ & $*$ & $*$ & & & & & & $*$ & $*$ & $*$ & $*$ & $*$ \\
\hline k04728 & $d-g$ & & $*$ & & & & $*$ & $*$ & - & $*$ & $*$ & - & & & & & & $*$ & $*$ & - & $*$ & $*$ \\
\hline k01355 & g-j & & $*$ & & & & $*$ & $*$ & $*$ & $*$ & $*$ & $*$ & & & & & & & $*$ & $*$ & $*$ & $*$ \\
\hline k04795 & g-j & & $*$ & & & & - & - & $*$ & $*$ & - & $*$ & & & & & & & $*$ & $*$ & $*$ & $*$ \\
\hline k00123 & g-j & & $*$ & & & & $*$ & $*$ & $*$ & $*$ & $*$ & $*$ & & & & & & & $*$ & $*$ & $*$ & $*$ \\
\hline k00620 & g-j & & $*$ & & & & $*$ & $*$ & $*$ & $*$ & $*$ & $*$ & & & & & & & $*$ & $*$ & $*$ & $*$ \\
\hline k02014 & g-j & & $*$ & & & & $*$ & $*$ & $*$ & $*$ & $*$ & $*$ & & & & & & & $*$ & $*$ & $*$ & $*$ \\
\hline k04158 & g-j & & $*$ & & & & $*$ & $*$ & $*$ & $*$ & $*$ & $*$ & & & & & & & $*$ & $*$ & $*$ & $*$ \\
\hline k04151 & g-j & & $*$ & & & & $*$ & $*$ & $*$ & $*$ & $*$ & $*$ & & & & & & & $*$ & $*$ & $*$ & $*$ \\
\hline k01438 & g-j & & $*$ & & & & $*$ & $*$ & $*$ & $*$ & $*$ & $*$ & & & & & & & $*$ & $*$ & - & $*$ \\
\hline k00812 & j-r & & $*$ & & & & $*$ & $*$ & $*$ & $*$ & $*$ & $*$ & & & & & & & & $*$ & $*$ & $*$ \\
\hline k04949 & j-r & & $*$ & & & & $*$ & $*$ & $*$ & $*$ & $*$ & $*$ & & & & & & & & $*$ & $*$ & $*$ \\
\hline k04068 & j-r & & $*$ & & & & $*$ & $*$ & $*$ & $*$ & $*$ & $*$ & & & & & & & & $*$ & $*$ & $*$ \\
\hline k03428 & j-r & & $*$ & & & & $*$ & $*$ & $*$ & $*$ & $*$ & $*$ & & & & & & & & $*$ & $*$ & $*$ \\
\hline k04134 & j-r & & $*$ & & & & $*$ & - & $*$ & $*$ & $*$ & $*$ & & & & & & & & $*$ & $*$ & $*$ \\
\hline k02730 & $\mathrm{r}-\mathrm{o}$ & & $*$ & & & & $*$ & - & $*$ & $*$ & $*$ & $*$ & & & & & & & & & $*$ & $*$ \\
\hline k01049 & o- & & $*$ & & & & $*$ & - & $*$ & $*$ & $*$ & $*$ & & & & & & & & & & \\
\hline k01176 & o- & & $*$ & & & & $*$ & $*$ & $*$ & $*$ & $*$ & $*$ & & & & & & & & & & \\
\hline k03158 & o- & & $*$ & & & & $*$ & $*$ & $*$ & $*$ & $*$ & $*$ & & & & & & & & & & \\
\hline k03130 & o- & & $*$ & & & & $*$ & $*$ & $*$ & $*$ & $*$ & $*$ & & & & & & & & & & \\
\hline k03448 & o- & & $*$ & & & & $*$ & $*$ & $*$ & $*$ & $*$ & $*$ & & & & & & & & & & \\
\hline k04741 & o- & & $*$ & & & & $*$ & $*$ & $*$ & $*$ & $*$ & - & & & & & & & & & & \\
\hline k00277 & o- & & $*$ & & & & $*$ & $*$ & $*$ & $*$ & $*$ & $*$ & & & & & & & & & & \\
\hline k00608 & o- & & $*$ & & & & $*$ & $*$ & $*$ & $*$ & $*$ & $*$ & & & & & & & & & & \\
\hline k04162 & o- & & $*$ & & & & $*$ & $*$ & $*$ & $*$ & $*$ & $*$ & & & & & & & & & & \\
\hline k00147 & $\begin{array}{l}\text { o- } \\
\text { Telomere }\end{array}$ & & $*$ & & & & $*$ & - & - & $*$ & $*$ & $*$ & & & & & & & & & & \\
\hline
\end{tabular}

1) “*” and "blank" represent the occurrence and absence of PCR amplification, respectively. “*?" and "_" indicates unexpected PCR amplification and unexpected absence of PCR amplification, respectively.

2) "a" to "s" indicate the positions of the breakpoints of the $7 \mathrm{H}$ structural aberrations.

genetic stocks for arranging barley EST markers along the chromosomes. The EST markers assigned to subarm regions would be useful for comparing physical and genetic maps of barley chromosomes (Künzel et al. 2000), and also for detecting the barley chromosome segments introduced into wheat (Taketa et al. 2005).
This study was partially supported by a Grant-in-Aid for Scientific Research (A) (No. 12306601) from the Ministry of Education, Science, Sports, and Culture, Japan, and a grant from CREST, JST, Japan. This is Contribution number 587 from the Laboratory of Plant Genetics, Graduate School of Agriculture, Kyoto University. 


\section{REFERENCES}

Becker, J., and Heun, M. (1995) Mapping of digested and undigested random amplified microsatellite polymorphisms in barley. Genome 38, 991-998.

Bennett, M. D., and Leitch I. J, (1995) Nuclear DNA amounts in Angiosperms. Ann. Bot. 76, 113-176.

Bennetzen, J. L. (2000) Comparative sequence analysis of plant nuclear genomes: microcolinearity and its many exceptions. Plant Cell 12, 1021-1030.

Bennetzen, J. L., and Ma, J. (2003) The genetic colinearity of rice and other cereals on the basis of genomic sequence analysis. Curr. Opin. Plant Biol. 6, 128-133.

Castiglioni, P., Pozzi, C., Heun, M., Terzi, V., Müller, K. J., Rohde, W., and Salamini, F. (1998) An AFLP-based procedure for the efficient mapping of mutations and DNA probes in barley. Genetics 149, 2039-2056.

Close, T. J., Wanamaker, S., Caldo, R. A., Turner, S. M., Ashlock, D. A., Dickerson, J. A., Wing, R. A., Muehlbauer, G. J., Kleinhofs, A., and Wise, R. P. (2004) A new resource for cereal genomics: $22 \mathrm{~K}$ barley GeneChip comes of age. Plant Physiol. 134, 960-968.

DeScenzo, R. A., and Wise, R. P. (1996) Variation in the ratio of physical to genetic distance in intervals adjacent to the Mla locus on barley chromosome 1H. Mol. Gen. Genet. 251, $472-482$.

Devos, K. M., and Gale M. D. (2000) Genome relationships: the grass model in current research. Plant Cell 12, 637-646.

Endo, T. R. (1988) Induction of chromosomal structural changes by a chromosome of Aegilops cylindrica L. in common wheat. J. Heredity 79, 366-370.

Endo, T. R. (1990) Gametocidal chromosomes and their induction of chromosome mutations in wheat. Jpn. J. Genet. 65, 135-152.

Endo, T. R., and Gill, B. S. (1996) The deletion stocks of common wheat. J. Heredity 87, 295-307.

Feuillet, C., and Keller, B. (2002) Comparative genomics in the grass family: molecular characterization of grass genome structure and evolution. Ann. Bot. 89, 3-10.

Gustafson, J. P., McGuire, P. E., and Qualset, C. O. (2004) Moving wheat into the mainstream in plant genomics. Genetics 168, 583-584.

Hori, K., Kobayashi, A., Shimizu, K., Sato, K., Takeda, K.,and Kawasaki, S. (2003) Efficient construction of high-density linkage map and its application to QTL analysis in barley. Theor. Appl. Genet. 107, 806-813.

Islam, A. K. M. R. (1983) Ditelosomic additions of barley chromosomes to wheat. In: Proc. 6th Intl. Wheat Genet. Symp. (ed.: Sakamoto S.), pp. 233-238. Plant Germplasm Institute, Kyoto, Japan.

Islam, A. K. M. R., and Shepherd K.W. (2000) Isolation of a fertile wheatg-barley addition line carrying the entire barley chromosome 1H. Euphytica 111, 145-149.

Islam, A. K. M. R., Shepherd, K. W., and Sparrow, H. B. (1981) Isolation and characterization of euplasmic wheat-barley chromosome addition lines. Heredity 46, 161-174.

Kleinhofs, A., Kilian, A., Saghai-Maroof, M. A., Biyashev, R. M., Hayes, P., Chen, F. Q., Lapitan, N., Fenwick, A., Blake, T. K., Kanazin, V., Ananiev, E., Dahleen, L., Kudrna, D., Bollinger, J., Knapp, S. J., Liu, B., Sorrells, M., Heun, M., Franckowiak, J. D., Hoffman, D., Skadsen, R., and Steffenson, B. J. (1993). A molecular, isozyme and morphological map of the barley (Hordeum vulgare) genome. Theor. Appl. Genet. 86, 705-712.
Künzel, G., Korzun, L., and Meister, A. (2000) Cytologically integrated physical restriction fragment length polymorphism maps for the barley genome based on translocation breakpoints. Genetics 154, 397-412.

Laurie, D. A., and Devos, K. M. (2002) Trends in comparative genetics and their potential impacts on wheat and barley research. Plant Mol. Biol. 48, 729-740.

Manninen, O., Kalender, R., Robinson, J., and Schulman, A. H. (2000) Application of BARE-1 retrotransposon markers to the mapping of a major resistance gene for net blotch in barley. Mol. Gen. Genet. 264, 325-334.

Murai, K., Taketa, S., Islam, A. K. M. R., and Shepherd, K. W. (2000) Barley allele-specific amplicons useful for identifying wheat-barley recombinant chromosomes. Genes Genet. Syst. 75, 131-139.

Nasuda, S., Hudakova, S., Schubert, I., Houben, A., and Endo, T. R. (2005) Stable barley chromosomes without centromeric repeats. Proc. Natl. Acad. Sci. USA 102, 9842-9847.

Qi, X., and Lindhout, P. (1997) Development of AFLP markers in barley. Mol. Gen. Genet. 254, 330-336.

Ramsay, L., Macaulay, M., degli Ivanissevich, S., MacLean, K., Cardle, L., Fuller, J., Edwards, K. J., Tuvesson, S., Morgante, M., Massari, A., Maestri, E., Marmiroli, N., Sjakste, T., Ganal, M., Powell, W., and Waugh, R. (2000) A simple sequence repeat-based linkage map of barley. Genetics 156, 1997-2005.

Saisho, D., Kawasaki, S., Sato, K., and Takeda, K. (2003) Construction and evaluation of a BAC library from Japanese malting barley 'Haruna Nijo.' In: Plant \& Animal Genomes XI, abstract 174 .

Sato K., Nankaku N., Motoi Y. and Takeda K. (2004) Large scale mapping of ESTs on barley genome. In: Proc. 9th Intl. Barley Genet. Symp., Vol.1 (eds.: Spunar J. and Janikova J.), pp. 79-85. Brno, Czech Republic.

Serizawa, N., Nasuda, S., Shi, F., Endo, T. R., Prodanovic, S., Schubert, I., and Künzel, G.. (2001a) Deletion-based physical mapping of barley chromosome $7 \mathrm{H}$. Theor. Appl. Genet. 103, 827-834.

Serizawa, N., Nasuda, S., and Endo T. R. (2001b) Barley chromosome addition lines of wheat for screening of AFLP markers on barley chromosomes. Genes Genet. Syst. 76, 107-110.

Shi, F., and Endo, T. R. (1997) Production of wheat-barley disomic addition lines possessing an Aegilops cylindrica gametocidal chromosome. Genes Genet. Syst. 72, 243-248.

Shi, F., and Endo, T. R. (1999) Genetic induction of structural changes in barley chromosomes added to common wheat by a gametocidal chromosome derived from Aegilops cylindrica. Genes Genet. Syst. 74, 49-54.

Shi, F., and Endo, T. R. (2000) Genetic induction of chromosomal rearrangements in barley chromosome $7 \mathrm{H}$ added to common wheat. Chromosoma 109, 358-363.

Sorokin, A., Marthe, F., Houben, A., Pich, U., Graner, A., and Künzel, G. (1994) Polymerase chain reaction mediated localization of RFLP clones to microisolated translocation chromosomes of barley. Genome 37, 550-555.

Taketa, S., Awayama, T., Ichii, M., Sunakawa, M., Kawahara, T., and Murai, K. (2005) Molecular cytogenetic identification of nullisomy 5B induced homoeologous recombination between wheat chromosome $5 \mathrm{D}$ and barley chromosome $5 \mathrm{H}$. Genome 48, 115-124.

Yu, Y., Tomkins, J. P., Waugh, R., Frisch, D. A., Kudrna, D., Kleinhofs, A., Brueggeman, R. S., Muehlbauer, G. J., Wise, R. P., and Wing, R. A. (2000) A bacterial artificial chromosome library for barley (Hordeum vulgare L.) and the iden- 
tification of clones containing putative resistance genes. Theor. Appl. Genet. 101, 1093-1099.

Werner, J. E., Endo, T. R., and Gill, B. S. (1992) Toward a cytogentically based physical map of the wheat genome. Proc.
Natl. Acad. Sci. USA 89, 11307-11311.

Zhang, H., Nasuda, S., and Endo T. R. (2000) Identification of AFLP markers on the satellite region of chromosome 1BS in wheat. Genome 43, 729-735. 